\title{
The emerging role of deubiquitinating enzymes in genomic integrity, diseases, and therapeutics
}

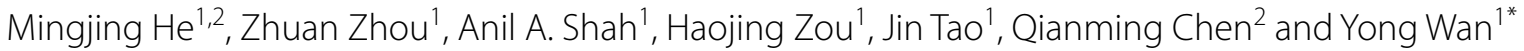

\begin{abstract}
The addition of mono-ubiquitin or poly-ubiquitin chain to signaling proteins in response to DNA damage signal is thought to be a critical event that facilitates the recognition of DNA damage lesion site, the activation of checkpoint function, termination and checkpoint response and the recruitment of DNA repair proteins. Despite the ubiquitin modifiers, removal of ubiquitin from the functional proteins by the deubiquitinating enzymes (DUBs) plays an important role in orchestrating DNA damage response as well as DNA repair processes. Deregulated ubiquitination and deubiquitination could lead to genome instability that in turn causes tumorigenesis. Recent TCGA study has further revealed the connection between mutations in alteration of DUBs and various types of tumors. In addition, emerging drug design based on DUBs provides a new avenue for anti-cancer therapy. In this review, we will summarize the role of deubiquitination and specificity of DUBs, and highlight the recent discoveries of DUBs in the modulation of ubiquitin-mediated DNA damage response and DNA damage repair. We will furthermore discuss the DUBs involved in the tumorigenesis as well as interception of deubiquitination as a novel strategy for anti-cancer therapy.
\end{abstract}

Keywords: Deubiquitinases, DNA damage response, DNA damage repair, Tumorigenesis, Anti-cancer treatment

\section{Background}

Genomic integrity is constantly challenged by DNA lesions produced as by-products of normal cellular metabolism, DNA replication or induced by radiation and toxic environmental chemicals. DNA damage could lead to detrimental effects on DNA replication and transcription, ultimately generating mutations and chromosomal aberrations that could contribute significantly to tumorigenesis. Upon DNA damage a series of guardian events occur, including the cellular recognition of DNA damage lesion site, initiation and amplification of DNA damage signal to activate DNA damage checkpoint function and activation of various type of DNA damage repair pathways are orchestrated by posttranslational modification, especially protein ubiquitination and deubiquitination, which preserve the genomic integrity.

\footnotetext{
*Correspondence: yow4@pitt.edu

1 Department of Cell Biology, University of Pittsburgh School of Medicine,

5117 Centre Avenue, Hillman Cancer Center, HCC2.6c, Pittsburgh, PA

15213, USA

Full list of author information is available at the end of the article
}

Ubiquitination, a posttranslational modification covalently attaching ubiquitin to targeted proteins, determines or alters protein's biological activity, stability or subcellular localization. Unlike the proteolytic regulation, a variety of DNA damage signaling modules are regulated by non-degrading ubiquitin-chain that result in the recruitment of DNA damage proteins to the damage site and activation of protein function. Like the balance of phosphorylation events by the phosphatases, the ubiquitination is counteracted by deubiquitinases.

Deubiquitinating enzymes (DUBs), proteases that reversely modify proteins by removing ubiquitin or ubiquitin-like molecules or remodeling ub-chains on target proteins, have recently be regarded as crucial regulators of both the ubiquitination-mediated degradation and other functions. Therefore, DUBs have a great influence on many biological processes and cellular pathways, including DNA damage response and DNA repair pathways. Thus, exploration of the in-depth mechanism by which DUBs regulate DNA damage response and 
DNA repair could provide new strategies for anti-cancer therapy.

\section{General roles of DUBs and DUBs specificity}

Ubiquitination, the process in which ubiquitin (Ub) that conjugate ubiquitin to targeted proteins through a cascade composed of E1, E2 and E3 enzymes, plays a vital role in multiple biological processes [1]. Ubiquitin contains seven lysine residues in total 76 amino acids and can form poly-ubiquitin chains of eight different linkages (K6, K11, K27, K29, K33, K48, K63, and Met1), as well as mixed and branched chains [2]. Distinct linkage types result in different chain conformations and display various functions such as protein degradation, localization or protein-protein interactions. For instance, protein degradation through the ubiquitin-proteasome system is mainly mediated by K6, K11, K27, K29, and K48 linked polyubiquitin chains [3]. However, K63 polyubiquitin chains are mainly contributed in the lysosomal pathway and endocytosis, DNA-repair, and signal transduction [4]. Besides, linear chains mediate NF- $\mathrm{kB}$ and Wnt signaling, cell death and appear to be required for angiogenic processes [5]. Single ubiquitin molecule could be conjugated to the substrate and is involved in the control of endocytosis, intravesicular transport, transcriptional regulation, DNA replication, and repair [6].

The reversal modification of adding ubiquitin to targeted proteins relies on deubiquitinating enzymes (DUBs), which catalytically cleave single Ub or polyubiquitin chains from proteins. The human genome encodes approximately 100 potential DUBs which can be classified into six families: ubiquitin-specific proteases (USPs), ubiquitin $\mathrm{COOH}$-terminal hydrolases (UCHs), ovarian tumor proteases (OTUs), Josephins, the JAB1/ MPN/MOV34 family (JAMMs) and motif interacting with Ub-containing novel DUB family (MINDYs) [7]. USPs, UCHs, OTUs, Josephins and the newly identified MINDYs families belong to thiol proteases, while the sixth, JAMMs, are $\mathrm{Zn}^{2+}$ metalloproteases [8].

\section{Main roles of DUBs}

The mechanism of protein degradation mediated by ubiquitin has been studied in depth, meanwhile, growing evidence reveals the non-proteolytic roles of ubiquitin modification. Here we will summarize the main roles of DUBs (Fig. 1).

\section{Counteracting the ubiquitin cascade Modulating E2 activity}

Generally, DUBs could inhibit ubiquitination by interfering with the formation and the reactivity of the E2-Ub intermediate. This is a mechanism that couples the opposing activities of the ubiquitination machinery in which DUBs maintain and modulate the dynamic balance of the ubiquitin-proteasome system catalytically or non-catalytically.

Ataxin-3, a DUB associated with Machado-Joseph disease, was reported to reduce the self-ubiquitination of parkin, a familiar form of Parkinson disease-associated E3 ubiquitin-ligase [9]. Intriguingly, Ataxin-3 is unable to remove pre-assembled ub-linkage on Parkin, but can regulate the formation of newly assembled Ub conjugates on Parkin by interacting with Parkin's E2 conjugating enzyme UbcH7 in a Parkin-depend manner [10]. The temporary formation of E2-parkin-Ataxin-3 complex contributes to the stabilization of E2 and Parkin interaction, impeding the dissociation of the uncharged E2 which can be recharged by E1, meanwhile diverting the $\mathrm{Ub}$ from the E2-Ub thioester conjugate onto Ataxin-3 itself, and away from parkin.

OTUB1 has recently emerged as a unique DUB that binds and inhibits several classes of E2s, including Ubc13 and UbcH5s, without reflecting DUB activity per se [11]. OTUB1 was shown to directly bind the Ub thiolester Ubc13 intermediate (Ubc13 Ub). The N-terminal residues of the OTU domain in OTUB1 are required for binding to $\mathrm{UBC} 13 \sim \mathrm{Ub}$ and this interaction is facilitated by the binding of a free Ub to a second site in OTUB1, resulting in allosteric change in the OTU domain and the formation of a ubiquitin-binding helix in the $\mathrm{N}$-terminus which increase its affinity for UBC13-Ub. By binding to OTUB1, UBC13-Ub could neither transfer ubiquitin nor bind to E3 ligase. Similarly, by predominately binding to "charged" UbcH5b, OTUB1 was concluded to function as an E2 inhibitor, reflected in preventing the auto-ubiquitination of the E3 ligase TRAF6.

USP7 is a deubiquitinating enzyme found in all eukaryotes that catalyzes the removal of ubiquitin from specific target proteins such as Mdm2, ICP0, and p53 [12]. USP7 could interact and forms a complex with an E2 ubiquitin conjugation enzyme, UbE2E1, requiring the $\mathrm{N}$-terminal ASTS sequence of UbE2E1. As a result of binding, UbE2E1-mediated ubiquitination was attenuated via the ASTS motif within its $\mathrm{N}$-terminal extension and the catalytic domain of USP7. Inactivation or disruption of the interaction between USP7 and UbE2E1 could lead to UbE2E1 destabilization as well [13].

\section{Counteracting E3s}

Many DUBs are associated with E3 ligases in pairs or complexes. DUBs co-regulate with E3 ligase partner to fine-tune the ubiquitin loading and removal of target proteins, which even refer to the E3 ligases when they could be self-ubiquitylated. The DUBs could be treated as prey when they are ubiquitinated by its E3 ligase partner or others. 


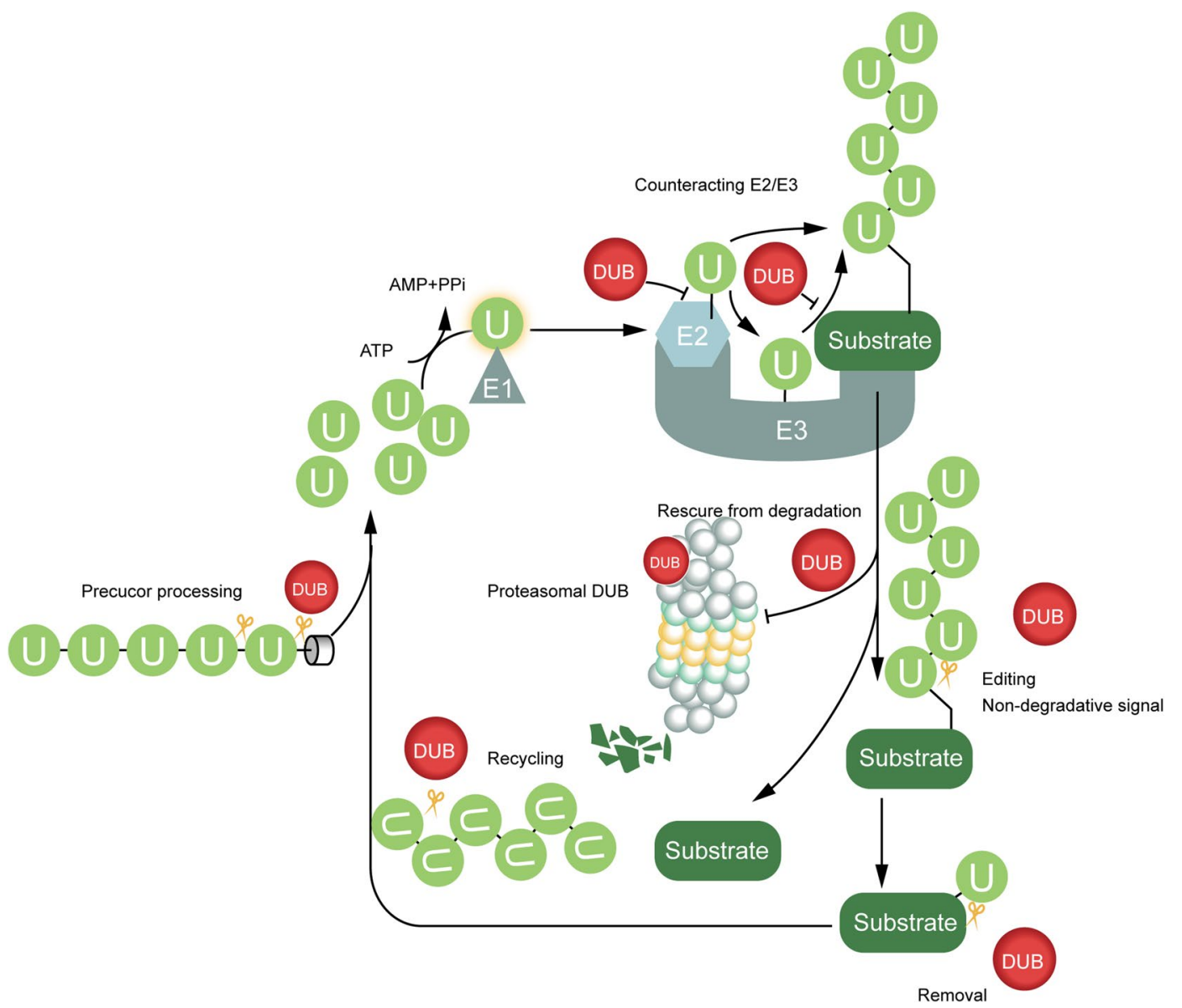

Fig. 1 Main roles of DUBs. Deubiquitination is involved in counteracting the ubiquitin cascade, including inhibiting E2 ubiquitin conjugating enzymes and E3 ligases. Proteasome related DUBs help to prevent degradation of ubiquitin chains of proteins treated. Lysosome-associated DUBs play crucial roles in receptor degradation and recycling. Alternatively, DUBs can remove or edit ubiquitin chains to change non-degradation ubiquitin signals. After releasing ubiquitin chains from proteins, DUBs are also responsible for the generation of free ubiquitin from ubiquitin precursors and the release of ubiquitin from unanchored isopeptide-linked ubiquitin chains into ubiquitin pool

USP10 is one of DUBs which regulate the stability of p53 both under physiological condition and in response to DNA damage with its E3 partner Mdm2. The main role of USP10 is to maintain the stable level of p53 in cytosol [14]. However, following DNA damage, part of USP10 translocate into nucleus to deubiquitylate p53 and thus boost p53 activation. With another E3 ligase partner Huwe1, USP10 appears to modulate the degradation of TATA-binding protein (TBP) during myogenesis [15]. In myoblasts, Huwe1 and USP10 co-operate to keep the homeostasis of TBP. Upon muscle differentiation stimulation, increased Huwe1 and declined USP10 lead to TBP ubiquitination and its proteasomal degradation.

A typical characteristic of E3 ligases is the ability of self-ubiquitination. Many E3 ligases catalyze their own ubiquitination in intermolecular or intramolecular mode, leading to degradation or non-proteolytic outcomes such as activity regulation. DUBs can reverse these ubiquitination events, modulating E3 ligase stability or activity and dynamically controlling the abundance of downstream substrates.

USP15 deubiquitylates autoubiquitinated Mdm2 to regulate p53 function and cancer-cell survival, while the stabilized Mdm2 negatively regulates $\mathrm{T}$ cell activation by targeting the transcription factor NFATc2 [16]. USP7 deubiquitinates ubiquitinated (by itself or external ligase such as E6AP) RING1B ligase of the polycomb complex [17]. Ataxin-3 interacts with monoubiquitinated CHIP and limits the length of the poly-ubiquitin chain of the target protein attached by CHIP. After this fine-tuned ubiquitylation is accomplished, Ataxin-3 removes the 
single ub from CHIP to terminate their interaction [18]. SMURF1, a Nedd4 family of HECT ubiquitin ligases, is self-ubiquitinated through its intrinsic HECT E3 ligase activity and marked a degradation signal, which is antagonized by USP9X via interacting with SMURF1 through the second WW domain of SMURF1 and the carboxyl terminus of USP9X [19].

Mdm2/USP7 and Ro52/USP4 are two E3/DUB pairs which are transregulated by each other. [20, 21]. When the substrate proteins are not required for degradation, the E3 ligases will be auto-ubiquitylated and their DUB partners are responsible for their stabilization. Conversely, USP 4 can be ubiquitylated by Ro52 and subsequently degraded.

\section{Assisting degradation machinery Proteasomal route related DUBs}

POH1/PSMD14/Rpn11 is a constitutive stoichiometric component in the $26 \mathrm{~S}$ proteasome "cap"-19S regulatory particle (RP) and is essential for the RP's assembly. POH1, belonging to metalloproteases subfamily JAMMs, is responsible for the hydrolysis of ub-chains before proteins are unfolded and degraded [22]. However, before deubiquitination of the substrate by $\mathrm{POH} 1$, two other DUBs UCH37 and Ubp6/USP14 antagonize protein degradation by trimming ubiquitin chains from the distal end of the chain leading to a decreased affinity of the protein for the proteasome [23, 24]. Unlike UCH37, USP14 not only removes single ubiquitin from Ub-chain but also bi- or tri-Ub, it can also preferentially remove ubiquitin chains en bloc from substrates with multiple ubiquitinated sites [25]. Besides, Ubp6 was also shown to stabilize the substrate via allosteric interference with the binding of the incoming substrate with the proteasome [24].

\section{Endocytic pathway related DUBs}

Research in endocytic pathways, especially the largely focused lysosomal degradation of cell-surface receptors, pointed out two DUBs, AMSH and USP8/UBPY [26, 27]. These two DUBs both localize to sorting endosomes through interactions with the endosomal sorting complex required for transport (ESCRT) components of the ESCRT machinery, mainly the ESCRT-0 component signal transducing adaptor molecule (STAM) and the ESCRT-III charged multivesicular body proteins (CHMPs) [28]. While both K63-specific DUB AMSH and non-ub-chain specific USP8 balance the receptor degradation and recycling, exhibiting negative regulation of lysosomal sorting, the roles of AMSH and USP8 are worthy of digging at depth [29]. AMSH and USP8 showed a positive role in the downregulation of protease-activated receptor 2 and additionally, USP8 exhibits pleiotropic effects considering its regulatory role in ESCRT-0 and receptors per se [30,31].

\section{Maintaining ubiquitin homeostasis}

Maintaining ubiquitin homeostasis includes the generation of Ub precursors from encoded genes, the trim of Ub precursors to free Ubs, the disassembly of polyubiquitin chains from proteins, and the recovery of Ub from chains and other inadvertently trapped Ub derivatives.

In mammals, four Ub precursors encoded by different genes are UBA52, UBA80, L40 and S27A, of which the former two are C-terminal single Ub fused to a ribosomal protein (Ub-RPs), and the rest two are Ub polymers linked in "a head to tail" mode followed by various amino acids in C-terminus (polyUbs). USP5 and Otulin/ Gumby/FAM105b preferentially catalyze polyUbs both co- and post-translationally, while UCHL3, USP9X and USP7 are found to be the main enzymes of Ub-RPs in charge in a form of post-translational modification [32]. USP5 is the major DUB which releases ubiquitin from unanchored isopeptide-linked ubiquitin chains, through the $\mathrm{ZnF}$-UBP domain that recognizes the free $\mathrm{C}$-terminus of ubiquitin [33].

\section{Specificity of DUBs \\ Cleavage specificity \\ Ub recognition}

The primary Ub binding site that DUB catalytic domains possess has substantial interactions with the distal Ub in a poly-ub chain mainly through Ile 44 patch, with different interacting surfaces among DUB subfamilies [34]. The C-terminus of the distal Ub forms a firmly held stretch from the binding site into the DUB catalytic center, allows DUBs to catalyze and distinguish Ub from other ubiquitin-like molecules (ULMs). The C-terminal sequence of Ub (Leu71, Arg72, Leu73, Arg74, Gly75, Gly76), is what makes it different from those of ULMs, and among these six amino acids, Arg74 and Gly75 are crucial for ubiquitin recognition by DUBs [35]. Due to possessing the same C-terminal sequence of Ub, a ULM interferon-stimulated gene 15 (ISG15) could be recognized by some DUBs [36]. However, USP18 can only cleave a linear fusion of ISG15 but not of ubiquitin, suggest the existence of different specify levels of DUBs [37].

\section{Linkage preference}

As the different conformations of diverse linkage types and chain lengths determine the Ub signals and thereby the fate of target proteins, it is not surprising that some DUBs have linkage specificity in the deubiquitylation reaction (Fig. 2). Most OTU or JAMM protease members show inherent specificity. For instance, OTUB1 has a striking specificity for K48-linked chains thus 


\section{Linkage preference Position specificity Direct/Indirect recognition}

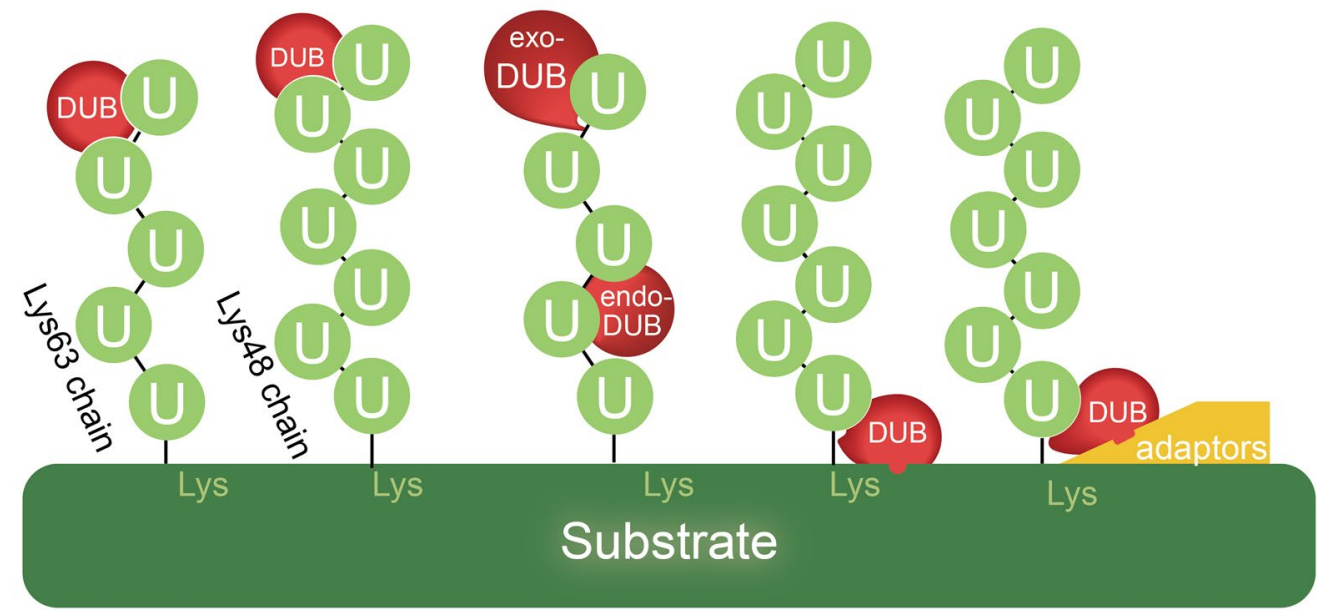

Fig. 2 Specificity of DUBs. The recognition and cleavage of ubiquitin chains requires multiple layers of specificity, including the distinguish of ubiquitin from ubiquitin-like molecules, the ubiquitin linkage preference, the position of cleavage site and the recognition of targeted proteins with or without the assistance of adaptors or scaffolds

protecting the substrates from degradation and $\mathrm{AMSH}$, AMSH-LP and BRCC3 prefer to cleave non-degradative K63-chains, while the OTULIN preferentially cleaves linear Ub chains $[11,38,39]$. On the other hand, other DUBs like USP family members display little linkage selectivity [40].

\section{Positioning specificity (exo-/endo-/mono-DUB)}

Ubiquitin chains can be cleaved from the distal part (exo) or internally (endo). USP14, as mentioned above, cleaves K48-linked chains from the distal end only (exo-activity), generating mono-ubiquitin [41]. In comparison, endocleavage could be observed in those non-degradative ubchains by DUBs such as CYLD and AMSH-LP [42, 43]. The positioning specificity could be explained based on DUB's structure difference. USP14 encompasses a finger subdomain which contacts up to $40 \%$ of the distal ubiquitin and blocks access to K48 or K63, allowing USP14 to bind to the distal end of an ubiquitin chain, but not to internal linkages. However, CYLD, due to the lack of the fingers subdomain, allows access to K63 [44, 45]. The cleavage of the first $\mathrm{Ub}$ molecule of a poly-ub chain requires DUBs with lower specificity of ub-chain linkage such as UCH subfamily members UCHL3, considering its role in processing precursor Ub [32]. Similarly, processing of monoubiquitin also requires non-specific DUBs which could adjust in their proximal binding site and also recognize the protein substrate [46]. The change of one chain type to another type, which would detour the fate of the substrate, would be easier for the protein with a proximal Ub left on.

\section{Substrate protein recognition}

Apart from linkage and positioning specificity, another feature of DUBs is substrate selectivity. As a consequence, many DUBs are found associated with substrates directly through the binding domains, or indirectly via adaptors and scaffolds.

Some DUBs display affinity for the ubiquitinated protein directly through their protein interaction domains. Crystal structure analysis showed that USP7 binds to its substrate p53 and its inhibitory interactor EpsteinBarr nuclear antigen 1 (EBNA1) protein through the same pocket but the former binding partner p53 exhibit weaker contacts with USP7 [47, 48]. Further functional studies indicated that EBNA1 binding to USP7 inhibits its interaction of $\mathrm{p} 53$ and protects cells from apoptotic challenge by lowering p53 levels [12].

Adaptors or scaffolds could facilitate the association between DUBs and substrates. Adaptor protein p62 binds to CYLD and recruits it to TRAF6 [49]. NEMO, another potential adaptor of CYLD, directly binds CYLD and associates with various IKK regulators, such as RIP1 and TRAF2 [50]. OTUD4, rather than being a DUB, acts as a scaffold for USP7 and USP9X, two DUBs that act directly on the DNA demethylases such as ALKBH2 and ALKBH3 [51]. Functionally, the loss of OTUD4, USP7, or USP9X in tumor cells leads to significantly increased 
sensitivity to alkylating agents. The translation initiation factor 3f (EIF3F) is recruited to activate Notch on endocytic vesicles by the Deltex1 serving as a bridging factor. Notch couldn't be processed by the gamma-secretase until it's deubiquitinated by EIF3F [52].

\section{DUBs and genomic integrity}

\section{DNA damage response main components and signaling}

In the face of the continuous threat from both exogenous and endogenous genotoxic insults, cells generate a complex network to maintain the genomic integrity, which is vital for various aspects of organism physiology, ranging from homeostasis to cancer prevention. DNA damage response (DDR), which includes surveillance proteins monitoring and detecting DNA damage, activating cell cycle checkpoints and ensure the effective DNA damage repair [53]. The checkpoint response can repair the damaged DNA before it passes on through mitosis, or make the decision of apoptosis if the damage is too difficult to repair [54]. DDR coordinates DNA repair with vital cellular functions to determine the fate of the cell after DNA damage [55]. As the fact that ubiquitination plays a prominent role in DDR, it could be expected that DUBs also serve as crucial regulators in DDR and DNA repair pathways (Fig. 3).

Various types of DNA lesions including DNA singleand double-strand breaks (SSBs and DSBs) are generated all the time in cells. Sensors such as MRN complex, Ku70/Ku80 heterodimer (KU) and PARPs are activated in response to DSBs (the former two) and SSBs [58]. FANCM, act as the sensor of interstrand crosslink (ICL)induced checkpoint response [59]. RPA binds to regions of exposed single-stranded DNA (ssDNA) in lesion area and the following events are the recruitment of ATM and ATRATRIP mediated by MRN and RPA respectively, the subsequent activation of the downstream pathways [60]. KU recruits DNA-PKcs to form the catalytically active DNAPK holoenzyme in the canonical non-homologous end joining (NHEJ) repair pathway [61]. On the other hand, MRN initiates homologous recombination (HR) [62].

Once activated, the cell-cycle checkpoint kinases CHK1 and CHK2 trigger the DNA damage signaling cascade to extend, gathering downstream effectors such as the p53 or the CDC25 and WEE1 [63]. Consequently, cyclindependent kinase (CDK) activity is inhibited, stalling cell cycle progression from $\mathrm{G} 1$ to $\mathrm{S}$ (the G1/S checkpoint) or from $G 2$ to $M$ phase (the G2/M checkpoint) [64]. The DDR thus masterminds a variety of events including the altered transcriptional program and the contemporarily arrested cell cycle, thereby facilitating repair of the DNA lesions. When DNA damage is too severe to be repaired, the fate of the damaged cell is apoptosis or senescence [65].
USP4 was found to interact with the DNA end resection factor CtIP and MRN complex via its C-terminal insert region and promoting the binding of CtIP/MRN by contracting its own ubiquitylation, which interfered with CtIP and MRN binding, thus impairing DNA end resection and HR [56]. UCH37, as previously mentioned, is a $19 \mathrm{~S}$ regulatory particle related DUB as well as a component of INO80 chromatin-remodeling complex which is known to directly associate with DSB ends and is required for DSB end resection and overall DSB repair $[66,67]$. Interestingly, Ku70 was found to function as a DUB to stabilize Mcl- 1 by directly interacting with $\mathrm{Mcl}-1$ via its $\mathrm{C}$-terminus, which is required and sufficient for deubiquitination and stabilization of Mcl-1, leading to suppression of apoptosis [68].

USP1 and USP7 are reported to be involved in deubiquitination and stabilization of Chk1 [69, 70]. USP7 was also shown to regulate other DDR proteins such as Claspin, an adaptor protein activated by Chk1 in the ATR-Chk1 pathway [71]. Importantly, the USP7 catalytic mutant is in a mono-ubiquitinated form, suggesting it is self-regulated by its hydrolase feature. Additionally, USP29 and USP20 were found to be other DUBs for Claspin, [72, 73].

The E3 ligase PIRH2 interacts with and ubiquitinates CHK2 dependent on its phosphorylation status. USP28 forms a complex with PIRH2 and CHK2 and antagonizes PIRH2-mediated polyubiquitylation and proteasomal degradation of CHK2 [74].

The ubiquitin modification of p53 is much complicated than that of other DDR components. Several E3 ligases target $\mathrm{p} 53$, of which Mdm2 plays a major role both in controlling basal levels of p53 in normal unstressed cells and in response to stress conditions [75]. Other E3 ubiquitin ligases identified include COP1, Pirh2, ARF-BP1, MSL2, and Parc [76-78]. On the other hands, several deubiquitinating enzymes to date have been identified targeting p53. These DUBs can target p53 directly or indirectly by regulating the E3 ligase Mdm2. USP7 was the first DUB identified to target p53 and Mdm2 for deubiquitination [79]. USP2a specifically deubiquitinates $\mathrm{Mdm} 2$ and $\mathrm{MdmX}$ [80]. In contrast to USP7 and USP2a, USP10 specifically deubiquitinate p53 because knockdown of USP10 in HCT116 p53-/cells does not cause Mdm2 reduction [14]. Importantly, USP10 can be phosphorylated by the ATM kinase, leading to its stabilization and nuclear translocation. Similarly, USP42 is a p53-specific deubiquitinase and plays a role in DNA damage-induced p53 stabilization [81]. USP24 is required for p53 stabilization in unstressed cells, as well as for p53 stabilization and PUMA activation after DNA damage [82]. Both OTUD5 and USP29 are required to be p53-dependent transcriptionally 


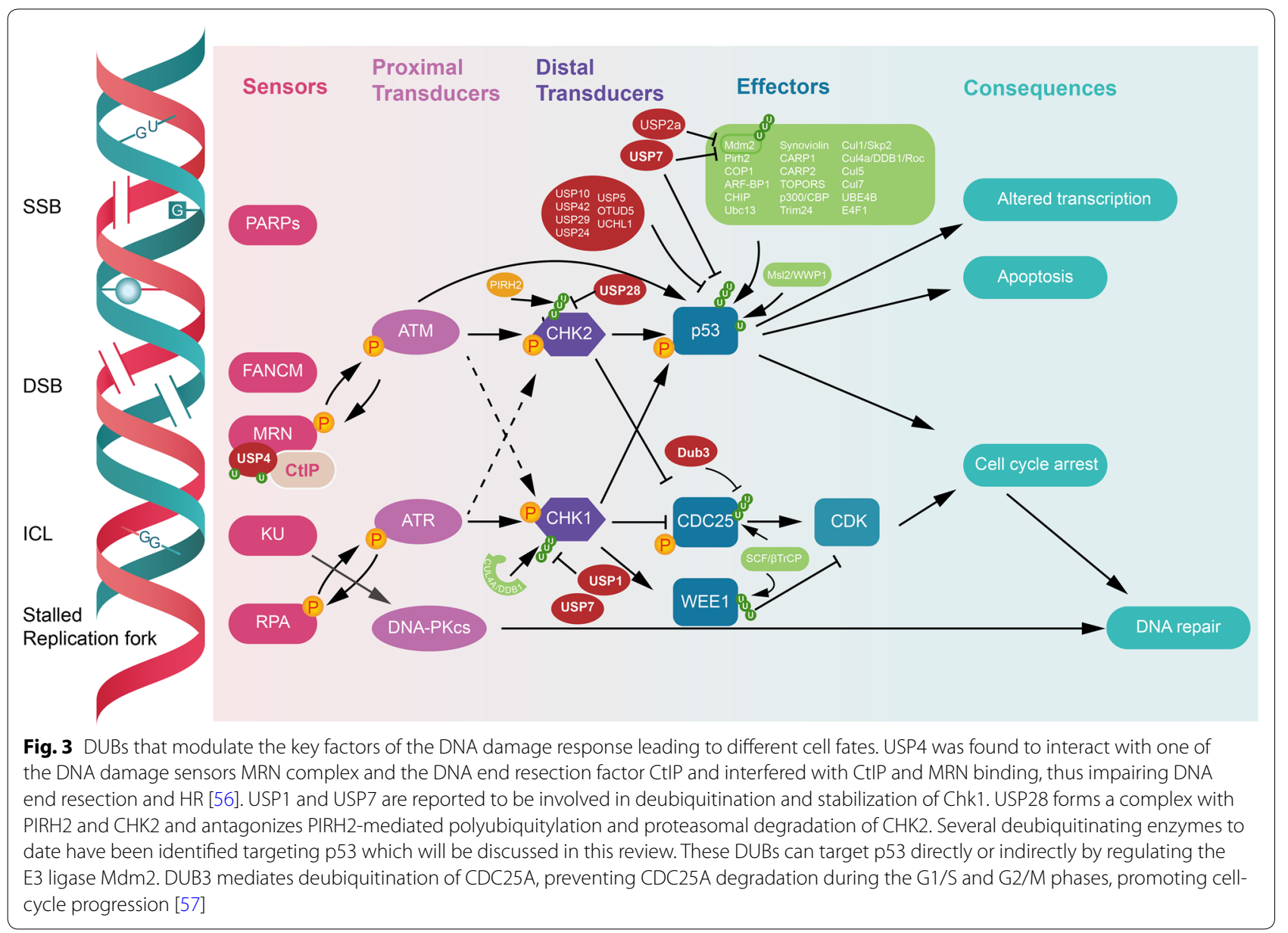

induced to stabilize p53 in response to DNA damage stress [83, 84]. Additionally, USP5 indirectly regulates levels of p53, while UCHL1 forms a complex with p53/ p14 (ARF)/Mdm2 p53 binding protein homolog in the mouse $[85,86]$. Recently, CYLD was shown to promote DNA damage-induced p53 stabilization and activation in epithelial cells and inhibit chemical carcinogeninduced intestinal and skin tumorigenesis [87]. Taken together, the varying actions of these deubiquitinases allow for dynamic p53 regulation in a context-dependent manner.

DUB3/USP17 mediates deubiquitination of CDC25A, preventing $\mathrm{CDC} 25 \mathrm{~A}$ degradation by the proteasome during the G1/S and G2/M phases promoting cell-cycle progression [57]. USP50 was identified as an interacting partner of HSP90. In response to DNA damage, USP50 accumulates in the nucleus and may act through an HSP90-dependent mechanism to counteract CDC25B mitotic inducing activity and prevent Weel degradation, thereby repressing entry into mitosis following activation of the DNA damage checkpoint [88].

\section{DNA damage repair}

DNA may be modified resulting from numerous genotoxic agents such as ultraviolet in the form of singlestrand breaks (SSBs) and/or double-strand breaks (DSBs) [89]. UV-induced damage also can result in the production of pyrimidine dimers and the formation of covalent cross-links [90]. Rapid and well-organized repair machinery composed of sensors and repair proteins are responsible for removing these lesions thus maintaining genomic integrity. Major repair pathways include base excision repair (BER), mismatch repair (MMR), nucleotide excision repair (NER), homologous recombination (HR), non-homologous end joining (NHEJ), and translesion synthesis (TLS) (Fig. 4) [91].

\section{Single strand break}

Since only one of the double strands of DNA is defective, the other strand could be used as a template. Taking advantage of this situation, several excision repair mechanisms exist, among which the BER repairs small base lesions while NER deals with bulky helix-distorting lesions. 


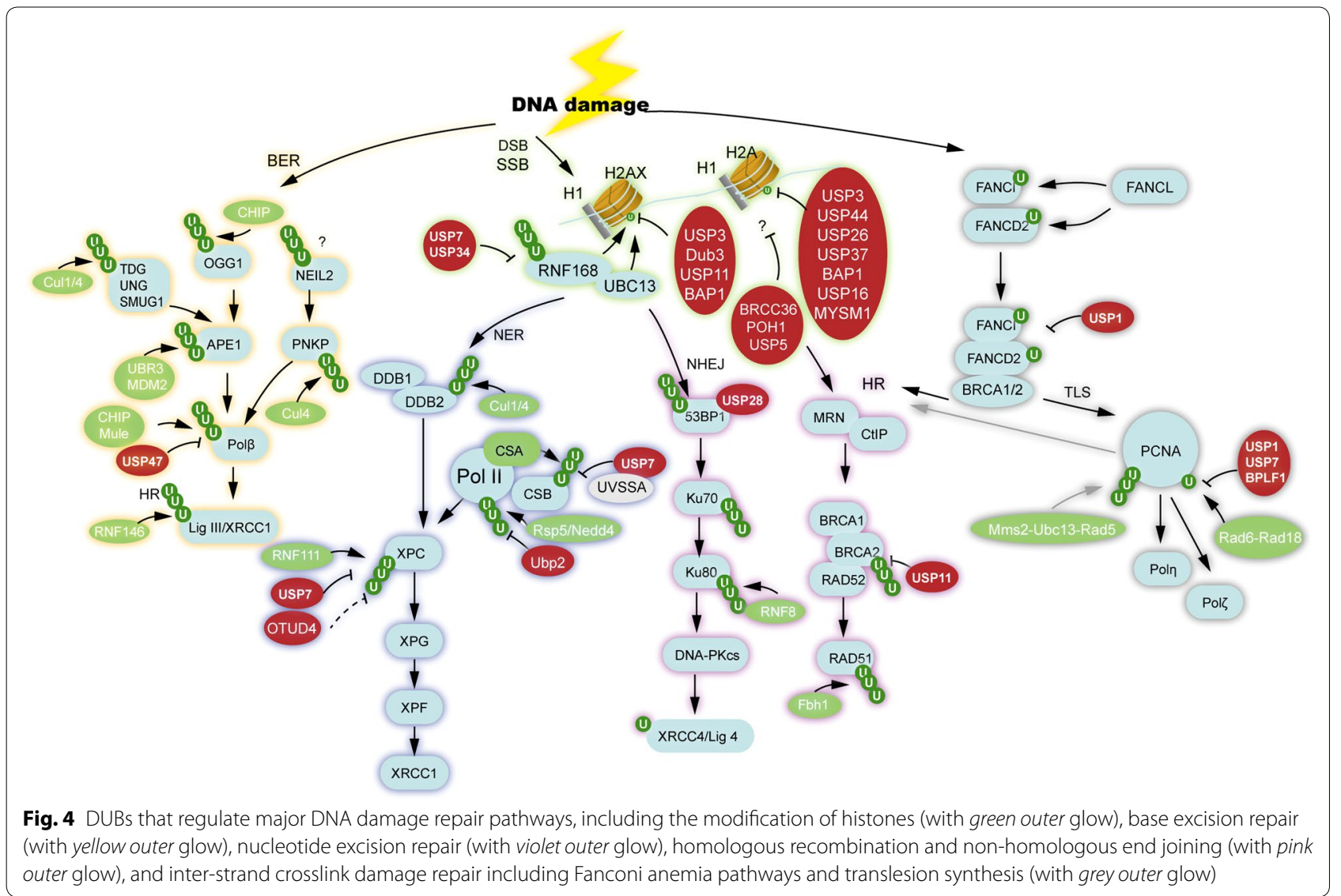

The initial step of BER is performed by DNA glycosylases, which scan along the DNA backbone to recognize and remove defective bases and form apurinic/apyrimidinic (AP) sites. These AP sites are then processed by AP endonuclease 1 (APE1) and DNA polymerase $\beta(\operatorname{Pol} \beta)$ to leave a single strand break and synthesize a new, no-error nucleotide. The final nick-sealing work is accomplished by DNA ligase III $\alpha$ (Lig III) along with its cofactor X-ray cross-complementing protein 1 (XRCC1) in short-patch BER. DNA ligase I ligates the break in long-patch BER [92]. Besides, endonuclease VIII-like proteins (NEIL1-3) have been identified as new human DNA glycosylases, with similar mistake elimination function but different lesion preferences [93].

USP47 is the major enzyme involved in deubiquitylation of Pol $\beta$. USP47 stabilizes the cytoplasmic Pol $\beta$ which will relocate to the nucleus in DNA damage pathway. Knockdown of USP47 decreased the level of Pol $\beta$ which defect the BER pathway, leading to accumulation of DNA strand breaks induced by DNA damaging agents [94].

NER repairs bulky DNA base adducts and ultraviolet light-induced lesions. NER can be divided into two main pathways based on the damage recognition mechanism: global genome repair (GG-NER) and transcription-coupled repair (TC-NER). The two pathways share the same processes in incision, repair, and ligation. DDB1-DDB2/ $\mathrm{XPE}$ and XPC/RAD23 complexes are responsible for damage detection in GG-NER [95].

DDB2, associates with DDB1, to recruit XPC to chromatin, and also facilitates the recruitment of cullin 4A/B-RING ubiquitin ligases which ubiquitinate various acceptor proteins including DDB2 and XPC [96]. When RNA polymerase II (RNAP II) stalls upon encountering a DNA lesion during transcription, TC-NER is activated and RNAP II is ubiquitinated and dislocated from chromatin. Recognition of damage is dependent on CSB (ERCC6), which associates with RNAP II and recruits CSA (ERCC8) to the lesions, the latter serves as E3 ligase of CSB in the CSA-CUL4A complex [97]. Reversibly, USP7 regulates NER targeting XPC protein and preventing XPC protein from undergoing UV-induced and $\mathrm{VCP} / \mathrm{p} 97$ regulated proteolysis [98]. Furthermore, USP7 and UVSSA protein couple and counteract CSAdependent degradation of CSB to allow sufficient time for CSB to perform its function in TC-NER when RNAP II is remodeling [99]. Proteolysis of damage-induced RNAP II is tightly regulated by both E3 ligases and DUB. 
In yeast, it has been shown that the degradation associated K48-linked ub chain is generated in 3 steps. Rsp5 E3 (NEDD4 in mammals) catalyzes K63-linked ub chain which is trimmed by a DUB Ubp2 resulting in the monoubiquitination of RNAP II, prompting a second E3 ligase Elongin/Cullin 3 complex to generate K48-linked ub chains [100].

\section{Double-strand break}

HR and NHEJ are two major DSB repair pathways. HR repair generates error-free strands by acquiring genetic information from sister chromatids, whereas NHEJ may lead to mutagenesis by ligating two broken ends directly, in which process the loss of the nucleotide in DSB may cause deletion and joining of non matching ends may cause insertions or translocations [101]. Increasing evidence has demonstrated the important role of DUBs in mediating the DSB repair pathways.

Post-translational modifications of histone, especially phosphorylation of H2AX by ATM and sequential recruitment of $\mathrm{MDC1}$, is the key initial event in DSB repair [102]. Phosphorylated MDC1 by ATM recruits E3 ligase RNF8 to add K63-ub chains to H1, forming a binding site for RNF168 to H1 [103]. Then RNF168 is ready to induce $\mathrm{K} 63-/ \mathrm{K} 27$-ubiquitination on $\mathrm{H} 2 \mathrm{~A}$, which in turn enhance the recruitment of RNF168 [104]. Besides, ubiquitination of H2B by RNF20-RNF40 is demonstrated to be crucial in response to DSB, as this ubiquitination event is important for the formation of open and biochemically accessible chromatin fiber that is conducive to DNA repair [105]. H1 and H2A may not be the respective substrates for RNF8 and RNF168 at DSB lesions. Recent studies have revealed that the polycomb molecule L3MBTL1 and the lysine demethylase JMJD2A are also substrates of RNF8 [106, 107]. RAP80 is a key factor at ubiquitinated structures on chromatin surrounding DSB sites. RAP80 facilitates the recruitment of BRCA1 to DSB sites as a scaffold molecule but the BRCA1-RAP80 complex limits nuclease accessibility to DSBs, thus preventing excessive end resection and potentially deleterious $\mathrm{HR}$ [108]. RAP80 also helps to recruit BRCC36, which regulates the NHEJ repair [109]. 53BP1, a key factor in NHEJ pathway, interacts tightly with nucleosomes containing both H4K20me2 and RNF168-dependent ubiquitinated histone H2A [110]. 53BP1 promotes the NHEJ pathway via the inhibition of BRCA1 recruitment, the recruitment of RIF1 and REV7 (anti-DNA end resection factors) and the recruitment of Artemis nuclease through PTIP [111].

DUBs of H2A and H2AX are partially shared. USP3, Dub3, USP11 and BAP1 show their DUB ability in H2AX-ub, while USP3, USP44, USP26, USP37, BAP1, USP16, and MYSM1 are DUBs which remove ubiquitin or ubiquitin chains from H2A. USP44 also can deubiquitinate H2B-Ub [112-115]. On the other hand, the stability of RNF168 is sustained by DUB USP34 and USP7. Recently, OTUB2 was suggested to target L3MBTL1 and K 63-linked ubiquitin chains to counteract the function of RNF8 and thus enhanced recruitment of 53BP1 and RAP80 [116]. USP11 was shown to interact with and deubiquitinates BRCA2 and as well counteracts RNF4-induced SUMO-ubiquitin hybrid chains, suggesting the pleiotropic roles at DSBs sites [117]. USP28 was shown to bind 53BP1, but only minor DDR defects were observed in USP28-depleted cells, suggesting its minor role in DSB repair. [118]. UCH37 was reported to regulate DSB resection and repair by HR pathway through stabilizing nuclear factor related to Kappa-B-binding protein (NFRKB) [66].

There are some DUBs found to be crucial in removing ub/ub-chains at DSB sites without clear substrates such as BRCC36, POH1, and USP5, which antagonize the K63-linked polyubiquitin conjugates at damage sites $[109,119]$.

\section{Interstrand crosslink}

ICLs are thought to be a highly toxic type of DNA damage which prevent transcription and replication. Defective repair of DNA of ICLs is a key feature of Fanconi anemia (FA). FA pathway is now thought to involve the coordination of HR, NER and TLS. There are currently 15 known genes (FANCA to FANCP) whose bi-allelic mutations yield FA [120].

Central to FA pathway is the monoubiquitination of FANCD2 (K-561) and FANCI (K-523) by the FA core subunit FANCL [121, 122]. This monoubiquitination is stimulated by DNA damage and it sends the signal to other FA proteins such as nucleases FANCP (SLX4) and FANCQ (XPF), and downstream repair factors like FANCJ (BRIP), FANCN (PALB2), FANCD1 (BRCA2), and FANCO (RAD51C) [120].

USP1 was one of the first ubiquitin hydrolases characterized as a key player in ICL repair pathways. USP1, the major DUB of FANCD2 and FANCI, inactivates these two proteins mediated by the USP1-activating factor UAF1 once DNA damage repair is finished [123].

DUBs indeed affect many other DNA damage repair processes, taking PCNA as an example. Under replication stress, PCNA is monoubiquitinated by the UBE2B-RAD18 and then recruits and activates potential error-prone DNA polymerases. Poly-ubiquitination of PCNA induced by E2 complex UBE2N-UBE2V2 and the E3 ligases HLTF, RNF8 and SHPRH makes it involved in an error-free template switching pathway [124]. USP1 and USP7 are identified as a DUB of mono-ubiquitinated PCNA acting in different cell cycle phases (S-phase and interphase respectively) $[46,125]$. Since PCNA is 
reported to associate with Epstein-Barr virus (EBV) DNA during its replication, an EBV DUB encoded by BPLF1 was found to target ubiquitinated PCNA and disrupts TLS [126].

\section{DUBs involved in diseases and DUBs targeting therapeutics}

Growing evidence indicates germline and somatic mutations, as well as expression frequency alterations of DUBs, are correlated with human disease, ranging from immune diseases to many human cancers.

\section{DUBs and diseases}

Mutations and deletions in CYLD have been reported in Brooke-Spiegler syndrome (BSS), familial trichoepithelioma and malignant transformation [127]. Mutated CYLD disrupted its inhibitory function on NF-kB and HDAC pathways, resulting in the activation of MYB, which plays a vital role in the biology of cylindroma either sporadic or emerged with BSS [128]. Additionally, CYLD has also be linked to immune response through its regulation on Tak1 with E3 ligase Itch, leading to the degradation of Tak1 resulting in the termination of inflammatory necrosis factor signaling [129]. A20 is another negative regulator of NF-kB pathway. A number of studies have reported the deletions or mutations of TNFAIP3 (encoding gene of A20) in lymphomas such as marginal zone lymphoma and Non-Hodgkin's lymphoma, indicating A20 as a tumor suppressor and immune regulator [130]. Recently, high penetrance heterozygous germline mutations in TNFAIP3 were considered as the cause of an auto-immune related syndrome Haplo insufficiency of A20 (HA20), displaying early-onset systemic inflammation, arthralgia/arthritis, oral/genital ulcers and ocular inflammation. Mutated A20 results in truncated proteins which is defective in inhibit NF-kB pathway, leading to an increased expression of NF-kB-mediated proinflammatory cytokines [131]. BAP1, as mentioned above, could remove ubiquitin from $\mathrm{H} 2 \mathrm{~A}$ in the complex with ASXL1 [132]. However, recent research revealed a new mechanism of loss of BAP1 contributing to tumorigenesis. By targeting atypical polycomb protein L3MBTL2, BAP1 interacts with and stabilizes L3MBTL2, co-occupying and maintaining H4K20me1 at target gene loci, such as EZH2 locus. Loss of BAP1 leads to reduced L3MBTL2 stability and increased EZH2 transcriptional output in mesothelioma [133]. USP8 gene somatic mutations are found in corticotroph adenomas, which results in pituitary corticotroph adenomas hypersecreting adrenocorticotropin (ACTH) and is the major cause of Cushing's disease. Mutated USP8 protein is truncated due to the loss of binding site for 14-3-3 protein and gains a higher DUB activity. This leads to increased recycling of its substrate
EGFR, which accumulates on plasma membrane and stimulates Pomc gene transcription and increase plasma ACTH levels [134].

Numbers of DUBs are associated with tumors by their alteration in protein expression. For instance, increased expression level of OTUD6B, UCH37, VCPIP1, USP7 and COPS5 are detected in breast cancer [135]. USP6 is considered as an oncogenic protein and overexpressed in primary aneurysmal bone cyst $(\mathrm{ABC})$ and nodular fasciitis by chromosome translocation, and forms fusion proteins with CDH11, TRAP150, ZNF9, OMD, and COL1A1, which result in promoter swapping and transcriptional up-regulation [136]. However, roles of some DUBs are poles apart in different tumor types. In ovarian and prostate carcinoma, USP2 protein is upregulated, whereas in colon cancer, USP2 expression is downregulated [137].

\section{Therapeutics targeting DUBs}

Specific mechanisms of deubiquitinating enzymes in various diseases have been described. Research should be concentrated on discovering an inhibitor on DUB's enzyme activity or antagonist which binds the substrates for therapy of cancer and other diseases (Table 1).

\section{DUB inhibition by compounds containing Michael acceptors}

Compounds containing Michael acceptors such as $\alpha$, $\beta$-unsaturated ketones have the inhibitory effect on some of cysteine DUBs due to the fact that they can potentially form covalent adducts with free thiols in the active site [138]. Cyclopentenone prostaglandins (PGs) of the PGJ2 class, chalcone compounds and other compounds containing Michael acceptors will be discussed here.

UCHL3 was found to be inhibited by $\Delta 12$-PGJ2 and UCHL1 by $15 \Delta$-PGJ2 [139]. Chalcone compounds G5 has a broad inhibitory spectrum, whereas another chalcone compounds b-AP15 and its analogue VLX1570 are relatively specific to USP14 and UCH37 [140, 141]. USP14 and UCH37, are also inhibited by curcumin analogue AC17 [142]. UCHL1, UCHL3, USP2 and USP8 were found to be inhibited by AM146, RA-9, and RA-14 which did not inhibit Ataxin-3, A20, BAP1, Otubain 1 or USP7 [143]. WP1130 acts as a partially selective DUB inhibitor for USP9x, USP5, USP14, and UCH37, resulting in downregulation of antiapoptotic and upregulation of proapoptotic proteins, such as MCL-1 and p53 [144]. Eeyarestatin-1 (Eer1) was identified to inhibit p97/VCPassociated DUB activity such as that of Ataxin-3 [145].

\section{Other small molecule DUB inhibitors}

Due to the multifaceted roles of USP7, many inhibitors have been developed targeting USP7, such as P022077, 
Table 1 DUB inhibitors

\begin{tabular}{|c|c|c|}
\hline Compound & Reported activity/target & Ref. \\
\hline \multicolumn{3}{|c|}{ Inhibitors containing Michael acceptors } \\
\hline $12 \triangle-P G J 2$ & UCHL3 & [139] \\
\hline $15 \Delta-P G J 2$ & UCHL1 & [139] \\
\hline G5 & Broad spectrum DUB inhibition & [140] \\
\hline b-AP15 & USP14/UCH37 & [141] \\
\hline VLX1570 & USP14/UCH37 & [141] \\
\hline AM146, RA-9 and RA-14 & USP2a/USP2b/USP5/USP8 & [143] \\
\hline WP1130 & $\begin{array}{l}\text { USP5/USP9x/USP14/UCHL1/ } \\
\text { UCHL5 }\end{array}$ & [144] \\
\hline Eeyarestatin 1 & Ataxin-3 & [145] \\
\hline \multicolumn{3}{|l|}{ Small inhibitors } \\
\hline AC17 & USP14/UCH37 & [142] \\
\hline P022077 & USP7 & [146] \\
\hline HBX 41, 108 & USP7 & [148] \\
\hline HBX-19, 818 & USP7 & [149] \\
\hline HBX-28, 258 & USP7 & [149] \\
\hline P5091 & USP7 & [147] \\
\hline Cpd 14 & USP7/USP47 & [150] \\
\hline P22077 & USP7/USP47 & [151] \\
\hline IU1 & USP14 & [139] \\
\hline LDN-57444 & UCHL1 & [152] \\
\hline LDN91946 & UCHL1 & [153] \\
\hline LS1 & UCHL3 & [156] \\
\hline PR-619 & Broad spectrum DUB inhibition & [157] \\
\hline 15-oxospiramilactone (S3) & USP30 & [158] \\
\hline \multicolumn{3}{|l|}{ Clinical drugs } \\
\hline Pimozide & USP1 & [154] \\
\hline Auranofin & proteasome-associated DUBs & [155] \\
\hline
\end{tabular}

HBX 41,108, HBX-19,818, HBX-28,258, P5091, Cpd 14 and P22077, in which the latter two molecules also inhibit USP47 [146-151]. A small molecule IU1 has been described as specific inhibitor of USP14, only binding the activated USP14 [139]. LDN-57444 is an isatin O-acyl oxime reported to selectively inhibit UCHL1 in a reversible, competitive, and active site-directed manner [152]. Compared to LDN-57444, LDN91946, 3-Amino-2-keto7H-thieno [2, 3-b] pyridin-6-one derivative, was discovered as moderately potent, non-competitive inhibitors of UCHL1 [153]. Clinical drugs for treating other diseases previously, were found as DUB inhibitors. Pimozide (an anti-psychotic drug) was identified as inhibitors of USP1, and auranofin (a rheumatoid arthritis drug) is a proteasome-associated DUB inhibitor $[154,155]$. Benefiting from high-throughput screening studies, LS1 as an UCHL3 inhibitor and PR-619 as a general DUB enzyme inhibitor [156, 157]. Interestingly, the mitochondrialocalized DUB USP30 was found to be inhibited by a diterpenoid derivative 15-oxospiramilactone (S3), leading to the increased Mfn1/2 proteins which promote mitochondrial fusion [158].

Of 100 DUBs, only several DUBs have been investigated for their structures despite identification of a variety of substrates for various DUBs, providing a rationale to open the way for designing small inhibitor molecules. 'To date only a few of DUB inhibitors such as VLX1570 are in clinical trials for tumor therapy. And no DUB inhibitor is approved for clinical use. Therefore, much work is still required to be accomplished to validate and develop them to the clinic.

\section{Conclusion}

While the impact of DUBs in the regulation of biological function and human diseases have attracted attention in the field for a decade, there are still quite a few aspects that have not been elucidated. Recent systematic screening of DUBs in regulating various cellular processes leads to diverse landscape of DUBs in regulating different pathways. An interesting puzzle needs to be explained is the observation of DUB substrates. At the biochemical level, how the substrate specificity is established for the limited 100 DUBs to face over thousands targeting proteins needs to be understood. Recently, some new findings enhance our knowledge regarding how DUBs interacts with the ubiquitin cascade. Despite the simple view of removal of ubiquitin chain from the substrate, it has been demonstrated that DUBs could modulate the activity of ubiquitin conjugating enzyme and directly counteract E3 ligase activity as well as to assist degradation machinery. Nevertheless, a better classification of 100 DUBs and their mechanism of counteracting ubiquitin cascade needs to be done. Other than conventional biochemical and cell biological dissection of the role of DUBs, more sophisticated protein structural studies could enhance our understanding of the in-depth mechanism of catalysis of deubiquitination and substrate specificity. As more missense mutations are described on DUBs in relation to tumorigenesis and various diseases, the physiological relevance of individual DUB and important mutation sites need to be validated by disease animal model. While a few DUB small molecule inhibitors shed light on anti-cancer therapy, more efforts are needed in drug development. Given our explored impact of DUBs in regulating DNA damage response and repair, it is important to determine the synergistic role of DUBs with current DNA damaging drugs in radiosensitization or chemosensitization of anti-cancer therapy.

\section{Abbreviations}

ABC: aneurysmal bone cyst; ACTH: hypersecreting adrenocorticotropin; AP: apurinic/apyrimidinic site; APE1: AP endonuclease 1; BER: base excision repair; BSS: Brooke-Spiegler syndrome; CDK: Cyclin-dependent kinase; CHMP: ESCRT-III charged multivesicular body protein; DDR: DNA damage response; DSB: double strand break; DUB: deubiquitinating enzyme; EBNA1: Epstein-Barr 
nuclear antigen 1; EBV: Epstein-Barr virus; Eer1: Eeyarestatin-1; EIF3F: translation initiation factor 3f; ESCRT: endosomal sorting complex required for transport; FA: Fanconi anemia; GG-NER: global genome repair; HR: homologous recombination; ICL: interstrand crosslink; ISG15: interferon-stimulated gene 15; JAMM: the JAB1/MPN/MOV34 family; KU: Ku70/Ku80 heterodimer; Lig III: DNA ligase Illa; MINDY: motif interacting with Ub-containing novel DUB family; MMR: mismatch repair; NEIL: endonuclease VIII-like protein; NER: nucleotide excision repair; NFRKB: kappa-B-binding protein; NHEJ: non-homologous end joining; OUT: ovarian tumor proteases; PG: prostaglandin; Pol $\beta$ : DNA polymerase $\beta$; RNAP II: RNA polymerase II; RP: 195 regulatory particle; SSB: single strand break; ssDNA: single-stranded DNA; STAM: signal transducing adaptor molecule; TBP: TATA-binding protein; TC-NER: transcription-coupled repair; TLS: translesion synthesis; Ub: ubiquitin; Ub-RP: ribosomal protein; $\mathrm{UCH}$ : ubiquitin COOH-terminal hydrolases; ULM: ubiquitin-like molecules; USP: ubiquitinspecific protease; XRCC1: X-ray cross-complementing protein 1.

\section{Authors' contributions}

$\mathrm{MJH}$ prepared the draft under the guidance of $\mathrm{YW} ; \mathrm{ZZ}, \mathrm{HJZ}$, JT and QMC contributed for discussion and revision; AS contributed to edit and improve the manuscript. All authors read and approved the final manuscript.

\section{Author details}

${ }^{1}$ Department of Cell Biology, University of Pittsburgh School of Medicine, 5117 Centre Avenue, Hillman Cancer Center, HCC2.6c, Pittsburgh, PA 15213, USA. ${ }^{2}$ State Key Laboratory of Oral Diseases, West China Hospital of Stomatology, Sichuan University, Chengdu 610041, Sichuan, People's Republic of China.

\section{Acknowledgements}

We are grateful to Wan members for their reading and discussion of the manuscript. This work was supported by grants from the National Institutes of Health (R01CA154695; R01CA202948; and R01CA202963).

\section{Competing interests}

The authors declare that they have no competing interests.

\section{Availability of data and materials}

Data sharing not applicable to this article as no datasets were generated or analyzed during the current study.

\section{Funding}

This work is funded by National Institutes of Health (R01CA154695;

R01CA202948; and R01CA202963).

Received: 30 September 2016 Accepted: 5 December 2016

Published online: 20 December 2016

\section{References}

1. Clague MJ, Heride C, Urbe $S$. The demographics of the ubiquitin system. Trends Cell Biol. 2015;25(7):417-26.

2. Ikeda F, Dikic I. Atypical ubiquitin chains: new molecular signals. ${ }^{\circledR}$ Protein modifications: beyond the usual suspects' review series. EMBO Rep. 2008;9(6):536-42.

3. Maupin-Furlow J. Proteasomes and protein conjugation across domains of life. Nat Rev Microbiol. 2012;10(2):100-11.

4. Erpapazoglou Z, Walker O, Haguenauer-Tsapis R. Versatile roles of k63linked ubiquitin chains in trafficking. Cells. 2014;3(4):1027-88.

5. I wai K, Fujita H, Sasaki Y. Linear ubiquitin chains: NF-kappaB signalling, cell death and beyond. Nat Rev Mol Cell Biol. 2014;15(8):503-8.

6. Ramanathan HN, Ye Y. Cellular strategies for making monoubiquitin signals. Crit Rev Biochem Mol Biol. 2012;47(1):17-28.

7. Pinto-Fernandez A, Kessler BM. DUBbing cancer: deubiquitylating enzymes involved in epigenetics, DNA damage and the cell cycle as therapeutic targets. Front Genet. 2016;7.

8. Rehman SA, Kristariyanto YA, Choi SY, Nkosi PJ, Weidlich S, Labib K, Hofmann K, Kulathu Y. MINDY-1 is a member of an evolutionarily conserved and structurally distinct new family of deubiquitinating enzymes. Mol Cell. 2016;63(1):146-55.
9. Matos CA, de Macedo-Ribeiro S, Carvalho AL. Polyglutamine diseases: the special case of ataxin-3 and Machado-Joseph disease. Prog Neurobiol. 2011;95(1):26-48.

10. Durcan TM, Kontogiannea M, Bedard N, Wing SS, Fon EA. Ataxin-3 deubiquitination is coupled to Parkin ubiquitination via E2 ubiquitinconjugating enzyme. J Biol Chem. 2012;287(1):531-41.

11. Wiener $R$, Zhang $X$, Wang $T$, Wolberger $C$. The mechanism of OTUB1mediated inhibition of ubiquitination. Nature. 2012;483(7391):618-22.

12. Nicholson B, Suresh Kumar KG. The multifaceted roles of USP7: new therapeutic opportunities. Cell Biochem Biophys. 2011;60(1-2):61-8.

13. Sarkari F, Wheaton K, La Delfa A, Mohamed M, Shaikh F, Khatun R, Arrowsmith CH, Frappier L, Saridakis V, Sheng Y. Ubiquitin-specific protease 7 is a regulator of ubiquitin-conjugating enzyme UbE2E1. J Biol Chem. 2013;288(23):16975-85.

14. Yuan J, Luo K, Zhang L, Cheville JC, Lou Z. USP10 regulates p53 localization and stability by deubiquitinating p53. Cell. 2010;140(3):384-96.

15. Li L, Martinez SS, Hu W, Liu Z, Tjian R. A specific E3 ligase/deubiquitinase pair modulates TBP protein levels during muscle differentiation. eLife. 2015;4:e08536.

16. Zou Q, Jin J, Hu H, Li HS, Romano S, Xiao Y, Nakaya M, Zhou X, Cheng X, Yang P, et al. USP15 stabilizes MDM2 to mediate cancer-cell survival and inhibit antitumor T cell responses. Nat Immunol. 2014;15(6):562-70.

17. de Bie P, Zaaroor-Regev D, Ciechanover A. Regulation of the polycomb protein RING1B ubiquitination by USP7. Biochem Biophys Res Commun. 2010;400(3):389-95.

18. Scaglione KM, Zavodszky E, Todi SV, Patury S, Xu P, Rodriguez-Lebron E, Fischer S, Konen J, Djarmati A, Peng J, et al. Ube2w and ataxin-3 coordinately regulate the ubiquitin ligase CHIP. Mol Cell. 2011;43(4):599-612.

19. Xie Y, Avello M, Schirle M, McWhinnie E, Feng Y, Bric-Furlong E, Wilson C, Nathans R, Zhang J, Kirschner MW, et al. Deubiquitinase FAM/USP9X interacts with the E3 ubiquitin ligase SMURF1 protein and protects it from ligase activity-dependent self-degradation. J Biol Chem. 2013;288(5):2976-85.

20. Clegg HV, Itahana K, Zhang Y. Unlocking the Mdm2-p53 loop: ubiquitin is the key. Cell Cycle. 2008;7(3):287-92.

21. Wada K, Kamitani T. UnpEL/Usp4 is ubiquitinated by Ro52 and deubiquitinated by itself. Biochem Biophys Res Commun. 2006;342(1):253-8.

22. Verma R, Aravind L, Oania R, McDonald WH, Yates JR 3rd, Koonin EV, Deshaies RJ. Role of Rpn11 metalloprotease in deubiquitination and degradation by the 265 proteasome. Science. 2002;298(5593):611-5.

23. Jacobson AD, MacFadden A, Wu Z, Peng J, Liu CW. Autoregulation of the 265 proteasome by in situ ubiquitination. Mol Biol Cell. 2014;25(12):1824-35.

24. Bashore C, Dambacher CM, Goodall EA, Matyskiela ME, Lander GC, Martin A. Ubp6 deubiquitinase controls conformational dynamics and substrate degradation of the 265 proteasome. Nat Struct Mol Biol. 2015;22(9):712-9.

25. Lee BH, Lu Y, Prado MA, Shi Y, Tian G, Sun S, Elsasser S, Gygi SP, King RW, Finley D. USP14 deubiquitinates proteasome-bound substrates that are ubiquitinated at multiple sites. Nature. 2016;532(7599):398-401.

26. McCullough J, Row PE, Lorenzo O, Doherty M, Beynon R, Clague MJ, Urbe S. Activation of the endosome-associated ubiquitin isopeptidase AMSH by STAM, a component of the multivesicular body-sorting machinery. Curr Biol. 2006;16(2):160-5.

27. Row PE, Liu H, Hayes S, Welchman R, Charalabous P, Hofmann K, Clague MJ, Sanderson CM, Urbe S. The MIT domain of UBPY constitutes a CHMP binding and endosomal localization signal required for efficient epidermal growth factor receptor degradation. J Biol Chem. 2007:282(42):30929-37.

28. Davies CW, Paul LN, Das C. Mechanism of recruitment and activation of the endosome-associated deubiquitinase AMSH. Biochemistry. 2013;52(44):7818-29.

29. MacDonald E, Urbe S, Clague MJ. USP8 controls the trafficking and sorting of lysosomal enzymes. Traffic. 2014;15(8):879-88.

30. Hasdemir B, Murphy JE, Cottrell GS, Bunnett NW. Endosomal deubiquitinating enzymes control ubiquitination and down-regulation of protease-activated receptor 2. J Biol Chem. 2009;284(41):28453-66.

31. Zhang J, Du J, Lei C, Liu M, Zhu AJ. Ubpy controls the stability of the ESCRT-0 subunit Hrs in development. Development. 2014;141(7):1473-9. 
32. Grou CP, Pinto MP, Mendes AV, Domingues P, Azevedo JE. The de novo synthesis of ubiquitin: identification of deubiquitinases acting on ubiquitin precursors. Sci Rep. 2015;5:12836.

33. Reyes-Turcu FE, Horton JR, Mullally JE, Heroux A, Cheng X, Wilkinson $\mathrm{KD}$. The ubiquitin binding domain $\mathrm{ZnF}$ UBP recognizes the C-terminal diglycine motif of unanchored ubiquitin. Cell. 2006;124(6):1197-208.

34. Dikic I, Wakatsuki S, Walters KJ. Ubiquitin-binding domains-from structures to functions. Nat Rev Mol Cell Biol. 2009;10(10):659-71.

35. Drag M, Mikolajczyk J, Bekes M, Reyes-Turcu FE, Ellman JA, Wilkinson KD, Salvesen GS. Positional-scanning fluorigenic substrate libraries reveal unexpected specificity determinants of DUBs (deubiquitinating enzymes). Biochem J. 2008;415(3):367-75.

36. Frias-Staheli N, Giannakopoulos NV, Kikkert M, Taylor SL, Bridgen A Paragas J, Richt JA, Rowland RR, Schmaljohn CS, Lenschow DJ, et al. Ovarian tumor domain-containing viral proteases evade ubiquitinand ISG15-dependent innate immune responses. Cell Host Microbe. 2007;2(6):404-16.

37. Malakhov MP, Malakhova OA, Kim KI, Ritchie KJ, Zhang DE. UBP43 (USP18) specifically removes ISG15 from conjugated proteins. J Biol Chem. 2002;277(12):9976-81.

38. Cooper EM, Cutcliffe C, Kristiansen TZ, Pandey A, Pickart CM, Cohen RE. K63-specific deubiquitination by two JAMM/MPN+ complexes: BRISC associated Brcc36 and proteasomal Poh1. EMBO J. 2009;28(6):621-31.

39. Fiil BK, Damgaard RB, Wagner SA, Keusekotten K, Fritsch M, BekkerJensen S, Mailand N, Choudhary C, Komander D, Gyrd-Hansen M. OTULIN restricts Met1-linked ubiquitination to control innate immune signaling. Mol Cell. 2013;50(6):818-30.

40. Iphofer A, Kummer A, Nimtz M, Ritter A, Arnold T, Frank R, van den Heuvel J, Kessler BM, Jansch L, Franke R. Profiling ubiquitin linkage specificities of deubiquitinating enzymes with branched ubiquitin isopeptide probes. ChemBioChem. 2012;13(10):1416-20.

41. Lee MJ, Lee BH, Hanna J, King RW, Finley D. Trimming of ubiquitin chains by proteasome-associated deubiquitinating enzymes. Mol Cell Proteom. 2011;10(5):R110003871.

42. Massoumi R. Ubiquitin chain cleavage: CYLD at work. Trends Biochem Sci. 2010;35(7):392-9.

43. Sato Y, Yoshikawa A, Yamagata A, Mimura H, Yamashita M, Ookata K, Nureki O, Iwai K, Komada M, Fukai S. Structural basis for specific cleavage of Lys 63-linked polyubiquitin chains. Nature. 2008:455(7211):358-62.

44. Komander D, Lord CJ, Scheel H, Swift S, Hofmann K, Ashworth A, Barford D. The structure of the CYLD USP domain explains its specificity for Lys63-linked polyubiquitin and reveals a B box module. Mol Cell. 2008;29(4):451-64.

45. Komander D. Mechanism, specificity and structure of the deubiquitinases. Sub-Cell Biochem. 2010;54:69-87.

46. Huang TT, Nijman SM, Mirchandani KD, Galardy PJ, Cohn MA, Haas W, Gygi SP, Ploegh HL, Bernards R, D'Andrea AD. Regulation of monoubiquitinated PCNA by DUB autocleavage. Nat Cell Biol. 2006;8(4):339-47.

47. Holowaty MN, Sheng Y, Nguyen T, Arrowsmith C, Frappier L. Protein interaction domains of the ubiquitin-specific protease, USP7/HAUSP. J Biol Chem. 2003;278(48):47753-61.

48. Saridakis V, Sheng Y, Sarkari F, Holowaty MN, Shire K, Nguyen T, Zhang RG, Liao J, Lee W, Edwards AM, et al. Structure of the p53 binding domain of HAUSP/USP7 bound to Epstein-Barr nuclear antigen 1 implications for EBV-mediated immortalization. Mol Cell. 2005;18(1):25-36.

49. Wooten MW, Geetha T, Babu JR, Seibenhener ML, Peng J, Cox N, Diaz-Meco MT, Moscat J. Essential role of sequestosome 1/p62 in regulating accumulation of Lys63-ubiquitinated proteins. J Biol Chem. 2008;283(11):6783-9.

50. Trompouki E, Hatzivassiliou E, Tsichritzis T, Farmer H, Ashworth A, Mosialos G. CYLD is a deubiquitinating enzyme that negatively regulates NF-KB activation by TNFR family members. Nature. 2003;424(6950):793-6.

51. Zhao Y, Majid MC, Soll JM, Brickner JR, Dango S, Mosammaparast N. Noncanonical regulation of alkylation damage resistance by the OTUD4 deubiquitinase. EMBO J. 2015;34(12):1687-703.

52. Moretti J, Chastagner P, Gastaldello S, Heuss SF, Dirac AM, Bernards R, Masucci MG, Israel A, Brou C. The translation initiation factor $3 f$ (elF3f) exhibits a deubiquitinase activity regulating Notch activation. PLOS Biol. 2010;8(11):e1000545.
53. Jackson SP, Bartek J. The DNA-damage response in human biology and disease. Nature. 2009;461(7267):1071-8.

54. Lopes M, Cotta-Ramusino C, Pellicioli A, Liberi G, Plevani P, Muzi-Falconi $M$, Newlon CS, Foiani M. The DNA replication checkpoint response stabilizes stalled replication forks. Nature. 2001;412(6846):557-61.

55. Giglia-Mari G, Zotter A, Vermeulen W. DNA damage response. Cold Spring Harb Perspect Biol. 2011;3(1):a000745.

56. Liu H, Zhang H, Wang X, Tian Q, Hu Z, Peng C, Jiang P, Wang T, Guo W, Chen Y, et al. The deubiquitylating enzyme USP4 cooperates with CtIP in DNA double-strand break end resection. Cell Rep. 2015;13(1):93-107.

57. Pereg Y, Liu BY, O'Rourke KM, Sagolla M, Dey A, Komuves L, French DM, Dixit VM. Ubiquitin hydrolase Dub3 promotes oncogenic transformation by stabilizing Cdc25A. Nat Cell Biol. 2010;12(4):400-6.

58. Ciccia A, Elledge SJ. The DNA damage response: making it safe to play with knives. Mol Cell. 2010;40(2):179-204.

59. Huang J, Liu S, Bellani MA, Thazhathveetil AK, Ling C, de Winter JP, Wang Y, Wang W, Seidman MM. The DNA translocase FANCM/MHF promotes replication traverse of DNA interstrand crosslinks. Mol Cell. 2013;52(3):434-46.

60. Falck J, Coates J, Jackson SP. Conserved modes of recruitment of ATM, ATR and DNA-PKCs to sites of DNA damage. Nature. 2005:434(7033):605-11.

61. Dobbs TA, Tainer JA, Lees-Miller SP. A structural model for regulation of NHEJ by DNA-PKcs autophosphorylation. DNA Repair (Amst). 2010;9(12):1307-14

62. Takeda S, Nakamura K, Taniguchi Y, Paull TT. Ctp1/CtIP and the MRN complex collaborate in the initial steps of homologous recombination. Mol Cell. 2007;28(3):351-2.

63. Bartek J, Lukas J. Chk1 and Chk2 kinases in checkpoint control and cancer. Cancer Cell. 2003;3(5):421-9.

64. Bartek J, Lukas J. Mammalian G1- and S-phase checkpoints in response to DNA damage. Curr Opin Cell Biol. 2001;13(6):738-47.

65. Fulda S. Cell death and survival signaling in oncogenesis. Klin Padiatr. 2010;222(6):340-4.

66. Chen X, Walters KJ. Structural plasticity allows UCH37 to be primed by RPN13 or locked down by INO80G. Mol Cell. 2015;57(5):767-8.

67. Yao T, Song L, Jin J, Cai Y, Takahashi H, Swanson SK, Washburn MP, Florens L, Conaway RC, Cohen RE, et al. Distinct modes of regulation of the Uch37 deubiquitinating enzyme in the proteasome and in the Ino80 chromatin-remodeling complex. Mol Cell. 2008;31(6):909-17.

68. Wang B, Xie M, Li R, Owonikoko TK, Ramalingam SS, Khuri FR, Curran WJ, Wang Y, Deng X. Role of Ku70 in deubiquitination of Mcl-1 and suppression of apoptosis. Cell Death Differ. 2014;21(7):1160-9.

69. Guervilly JH, Renaud E, Takata M, Rosselli F. USP1 deubiquitinase maintains phosphorylated CHK1 by limiting its DDB1-dependent degradation. Hum Mol Genet. 2011;20(11):2171-81.

70. Alonso-de Vega I, Martin Y, Smits VA. USP7 controls Chk1 protein stability by direct deubiquitination. Cell Cycle. 2014;13(24):3921-6.

71. Faustrup H, Bekker-Jensen S, Bartek J, Lukas J, Mailand N. USP7 counteracts SCFbetaTrCP-but not APCCdh1-mediated proteolysis of Claspin. J Cell Biol. 2009;184(1):13-9.

72. Martin Y, Cabrera E, Amoedo H, Hernandez-Perez S, Dominguez-Kelly R, Freire R. USP29 controls the stability of checkpoint adaptor Claspin by deubiquitination. Oncogene. 2015;34(8):1058-63.

73. Yuan J, Luo K, Deng M, Li Y, Yin P, Gao B, Fang Y, Wu P, Liu T, Lou Z. HERC2-USP20 axis regulates DNA damage checkpoint through Claspin. Nucleic Acids Res. 2014;42(21):13110-21.

74. Bohgaki M, Hakem A, Halaby MJ, Bohgaki T, Li Q, Bissey PA, Shloush J, Kislinger T, Sanchez O, Sheng Y, et al. The E3 ligase PIRH2 polyubiquitylates CHK2 and regulates its turnover. Cell Death Differ. 2013;20(6):812-22.

75. Moll UM, Petrenko O. The MDM2-p53 interaction. Mol Cancer Res. 2003;1(14):1001-8.

76. Dornan D, Wertz I, Shimizu H, Arnott D, Frantz GD, Dowd P, O'Rourke $\mathrm{K}$, Koeppen H, Dixit VM. The ubiquitin ligase COP1 is a critical negative regulator of p53. Nature. 2004;429(6987):86-92.

77. Leng RP, Lin Y, Ma W, Wu H, Lemmers B, Chung S, Parant JM, Lozano G, Hakem R, Benchimol S. Pirh2, a p53-induced ubiquitin-protein ligase, promotes p53 degradation. Cell. 2003;112(6):779-91.

78. Brooks CL, Gu W. p53 ubiquitination: Mdm2 and beyond. Mol Cell. 2006;21(3):307-15. 
79. Sheng Y, Saridakis V, Sarkari F, Duan S, Wu T, Arrowsmith CH, Frappier L. Molecular recognition of p53 and MDM2 by USP7/HAUSP. Nat Struct Mol Biol. 2006;13(3):285-91.

80. Stevenson LF, Sparks A, Allende-Vega N, Xirodimas DP, Lane DP, Saville MK. The deubiquitinating enzyme USP2a regulates the p53 pathway by targeting Mdm2. EMBO J. 2007;26(4):976-86.

81. Hock AK, Vigneron AM, Carter S, Ludwig RL, Vousden KH. Regulation of p53 stability and function by the deubiquitinating enzyme USP42. EMBO J. 2011:30(24):4921-30.

82. Zhang L, Nemzow L, Chen H, Lubin A, Rong X, Sun Z, Harris TK, Gong F. The deubiquitinating enzyme USP24 is a regulator of the UV damage response. Cell Rep. 2015;10(2):140-7.

83. Luo J, Lu Z, Lu X, Chen L, Cao J, Zhang S, Ling Y, Zhou X. OTUD5 regulates p53 stability by deubiquitinating p53. PLoS ONE. 2013;8(10):e77682.

84. Liu J, Chung HJ, Vogt M, Jin Y, Malide D, He L, Dundr M, Levens D. JTV1 co-activates FBP to induce USP29 transcription and stabilize p53 in response to oxidative stress. EMBO J. 2011;30(5):846-58.

85. Dayal S, Sparks A, Jacob J, Allende-Vega N, Lane DP, Saville MK. Suppression of the deubiquitinating enzyme USP 5 causes the accumulation of unanchored polyubiquitin and the activation of p53. J Biol Chem. 2009;284(8):5030-41.

86. Li L, Tao Q, Jin H, van Hasselt A, Poon FF, Wang X, Zeng MS, Jia WH, Zeng YX, Chan AT, et al. The tumor suppressor UCHL1 forms a complex with p53/MDM2/ARF to promote p53 signaling and is frequently silenced in nasopharyngeal carcinoma. Clin Cancer Res. 2010;16(11):2949-58.

87. Ke H, Augustine CK, Gandham VD, Jin JY, Tyler DS, Akiyama SK, Hall RP, Zhang JY. CYLD inhibits melanoma growth and progression through suppression of the JNK/AP-1 and beta1-integrin signaling pathways. J Invest Dermatol. 2013;133(1):221-9.

88. Aressy B, Jullien D, Cazales M, Marcellin M, Bugler B, Burlet-Schiltz O, Ducommun B. A screen for deubiquitinating enzymes involved in the G(2)/M checkpoint identifies USP50 as a regulator of HSP90-dependent Wee1 stability. Cell Cycle. 2010;9(18):3815-22.

89. Ward JF, Evans JW, Limoli CL, Calabro-Jones PM. Radiation and hydrogen peroxide induced free radical damage to DNA. Br J Cancer Suppl. 1987:8:105-12.

90. Cadet J, Sage E, Douki T. Ultraviolet radiation-mediated damage to cellular DNA. Mutat Res. 2005:571(1-2):3-17.

91. Helleday T, Petermann E, Lundin C, Hodgson B, Sharma RA. DNA repair pathways as targets for cancer therapy. Nat Rev Cancer. 2008;8(3):193-204.

92. Krokan HE, Bjørås M. Base excision repair. Cold Spring Harb Perspect Biol. 2013;5(4):a012583.

93. Grin I, Zharkov D. Eukaryotic endonuclease VIII-like proteins: new components of the base excision DNA repair system. Biochem (Moscow). 2011;76(1):80-93.

94. Parsons JL, Dianova II, Khoronenkova SV, Edelmann MJ, Kessler BM, Dianov GL. USP47 is a deubiquitylating enzyme that regulates base excision repair by controlling steady-state levels of DNA polymerase $\beta$. Mol Cell. 2011:41(5):609-15.

95. Schärer OD. Nucleotide excision repair in eukaryotes. Cold Spring Harb Perspect Biol. 2013;5(10):a012609.

96. Ray A, Milum K, Battu A, Wani G, Wani AA. NER initiation factors, DDB2 and $X P C$, regulate UV radiation response by recruiting ATR and ATM kinases to DNA damage sites. DNA Repair. 2013;12(4):273-83.

97. Fousteri M, Mullenders LH. Transcription-coupled nucleotide excision repair in mammalian cells: molecular mechanisms and biological effects. Cell Res. 2008;18(1):73-84.

98. He J, Zhu Q, Wani G, Sharma N, Han C, Qian J, Pentz K, Wang QE, Wani AA. Ubiquitin-specific protease 7 regulates nucleotide excision repair through deubiquitinating XPC protein and preventing XPC protein from undergoing ultraviolet light-induced and VCP/p97 protein-regulated proteolysis. J Biol Chem. 2014;289(39):27278-89.

99. Schwertman P, Lagarou A, Dekkers DH, Raams A, van der Hoek AC, Laffeber C, Hoeijmakers JH, Demmers JA, Fousteri M, Vermeulen W, et al. UV-sensitive syndrome protein UVSSA recruits USP7 to regulate transcription-coupled repair. Nat Genet. 2012;44(5):598-602.

100. Harreman M, Taschner M, Sigurdsson S, Anindya R, Reid J, Somesh B, Kong SE, Banks CA, Conaway RC, Conaway JW. Distinct ubiquitin ligases act sequentially for RNA polymerase II polyubiquitylation. Proc Natl Acad Sci. 2009;106(49):20705-10.
101. Chapman JR, Taylor MR, Boulton SJ. Playing the end game: DNA double-strand break repair pathway choice. Mol Cell. 2012;47(4):497-510.

102. Price BD, D'Andrea AD. Chromatin remodeling at DNA double-strand breaks. Cell. 2013;152(6):1344-54.

103. Kolas NK, Chapman JR, Nakada S, Ylanko J, Chahwan R, Sweeney FD, Panier S, Mendez M, Wildenhain J, Thomson TM. Orchestration of the DNA-damage response by the RNF8 ubiquitin ligase. Science. 2007;318(5856):1637-40.

104. Gatti M, Pinato S, Maspero E, Soffientini P, Polo S, Penengo L. A novel ubiquitin mark at the $\mathrm{N}$-terminal tail of histone $\mathrm{H} 2 \mathrm{As}$ targeted by RNF168 ubiquitin ligase. Cell Cycle. 2012:11(13):2538-44.

105. Chernikova SB, Razorenova OV, Higgins JP, Sishc BJ, Nicolau M, Dorth JA, Chernikova DA, Kwok S, Brooks JD, Bailey SM. Deficiency in mammalian histone H2B ubiquitin ligase Bre1 (Rnf20/Rnf40) leads to replication stress and chromosomal instability. Cancer Res. 2012;72(8):2111-9.

106. Mallette FA, Mattiroli F, Cui G, Young LC, Hendzel MJ, Mer G, Sixma TK, Richard S. RNF8-and RNF168-dependent degradation of KDM4A/ JMJD2A triggers 53BP1 recruitment to DNA damage sites. EMBO J. 2012;31(8):1865-78

107. Acs K, Luijsterburg MS, Ackermann L, Salomons FA, Hoppe T, Dantuma NP. The AAA-ATPase VCP/p97 promotes 53BP1 recruitment by removing L3MBTL1 from DNA double-strand breaks. Nat Struct Mol Biol. 2011;18(12):1345-50.

108. Sobhian B, Shao G, Lilli DR, Culhane AC, Moreau LA, Xia B, Livingston DM, Greenberg RA. RAP80 targets BRCA1 to specific ubiquitin structures at DNA damage sites. Science. 2007;316(5828):1198-202.

109. Shao G, Lilli DR, Patterson-Fortin J, Coleman KA, Morrissey DE, Greenberg RA. The Rap80-BRCC36 de-ubiquitinating enzyme complex antagonizes RNF8-Ubc13-dependent ubiquitination events at DNA double strand breaks. Proc Natl Acad Sci. 2009;106(9):3166-71.

110. Panier S, Boulton SJ. Double-strand break repair: 53BP1 comes into focus. Nat Rev Mol Cell Biol. 2014;15(1):7-18.

111. Ochs F, Somyajit K, Altmeyer M, Rask M-B, Lukas J, Lukas C. 53BP1 fosters fidelity of homology-directed DNA repair. Nat Struct Mol Biol. 2016.

112. Sharma N, Zhu Q, Wani G, He J, Wang QE, Wani AA. SP3 counteracts RNF168 via deubiquitinating $\mathrm{H} 2 \mathrm{~A}$ and gammaH2AX at lysine 13 and 15 . Cell Cycle. 2014;13(1):106-14.

113. Delgado-Diaz MR, Martin Y, Berg A, Freire R, Smits VA. Dub3 controls DNA damage signalling by direct deubiquitination of H2AX. Mol Oncol. 2014:8(5):884-93.

114. Yu M, Liu K, Mao Z, Luo J, Gu W, Zhao W. USP11 is a negative regulator to gammaH2AX ubiquitylation by RNF8/RNF168. J Biol Chem. 2015.

115. Sahtoe DD, van Dijk WJ, Ekkebus R, Ovaa H, Sixma TK. BAP1/ASXL1 recruitment and activation for $\mathrm{H} 2 \mathrm{~A}$ deubiquitination. Nat Commun. 2016;7:10292.

116. Kato K, Nakajima K, Ui A, Muto-Terao Y, Ogiwara H, Nakada S. Finetuning of DNA damage-dependent ubiquitination by OTUB2 supports the DNA repair pathway choice. Mol Cell. 2014;53(4):617-30.

117. Schoenfeld AR, Apgar S, Dolios G, Wang R, Aaronson SA. BRCA2 is ubiquitinated in vivo and interacts with USP11, a deubiquitinating enzyme that exhibits prosurvival function in the cellular response to DNA damage. Mol Cell Biol. 2004;24(17):7444-55.

118. Knobel PA, Belotserkovskaya R, Galanty Y, Schmidt CK, Jackson SP, Stracker TH. USP28 is recruited to sites of DNA damage by the tandem BRCT domains of 53BP1 but plays a minor role in double-strand break metabolism. Mol Cell Biol. 2014;34(11):2062-74.

119. Kakarougkas A, Ismail A, Katsuki Y, Freire R, Shibata A, Jeggo PA. Cooperation of BRCA1 and $\mathrm{POH} 1$ relieves the barriers posed by 53BP1 and RAP80 to resection. Nucleic Acids Res. 2013;41(22):10298-311.

120. Walden $H$, Deans AJ. The Fanconi anemia DNA repair pathway: structural and functional insights into a complex disorder. Annu Rev Biophys. 2014:43:257-78.

121. Meetei AR, Yan Z, Wang W. FANCL replaces BRCA1 as the likely ubiquitin ligase responsible for FANCD2 monoubiquitination. Cell Cycle. 2004;3(2):174-6.

122. Sims AE, Spiteri E, Sims RJ, Arita AG, Lach FP, Landers T, Wurm M, Freund $M$, Neveling $K$, Hanenberg $\mathrm{H}$. FANCl is a second monoubiquitinated member of the Fanconi anemia pathway. Nat Struct Mol Biol. 2007;14(6):564-7.

123. Kim M, Kim JM. The role of USP1 auto-cleavage in DNA inter-strand crosslink repair. FEBS Lett. 2016;590:340-8. 
124. Brown S, Niimi A, Lehmann AR. Ubiquitination and deubiquitination of PCNA in response to stalling of the replication fork. Cell Cycle. 2009;8(5):689-92

125. Qian J, Pentz K, Zhu Q, Wang Q, He J, Srivastava AK, Wani AA. USP7 modulates UV-induced PCNA monoubiquitination by regulating DNA polymerase eta stability. Oncogene. 2015;34(36):4791-6.

126. Whitehurst CB, Vaziri C, Shackelford J, Pagano JS. Epstein-Barr virus BPLF1 deubiquitinates PCNA and attenuates polymerase eta recruitment to DNA damage sites. J Virol. 2012;86(15):8097-106.

127. Bowen S, Gill M, Lee DA, Fisher G, Geronemus RG, Vazquez ME, Celebi JT. Mutations in the CYLD gene in Brooke-Spiegler syndrome, familial cylindromatosis, and multiple familial trichoepithelioma: lack of genotype-phenotype correlation. J Investig Dermatol. 2005;124(5):919-20.

128. Corda G, Sala A. Cutaneous cylindroma: it's all about MYB. J Pathology. 2016.

129. Ahmed N, Zeng M, Sinha I, Polin L, Wei WZ, Rathinam C, Flavell R, Massoumi R, Venuprasad K. The E3 ligase Itch and deubiquitinase Cyld act together to regulate Tak1 and inflammation. Nat Immunol. 2011;12(12):1176-83.

130. Schmitz R, Hansmann ML, Bohle V, Martin-Subero Jl, Hartmann S, Mechtersheimer G, Klapper W, Vater I, Giefing M, Gesk S. TNFAIP3 (A20) is a tumor suppressor gene in Hodgkin lymphoma and primary mediastinal B cell lymphoma. J Exp Med. 2009;206(5):981-9.

131. Zhou Q, Wang H, Schwartz DM, Stoffels M, Park YH, Zhang Y, Yang D, Demirkaya E, Takeuchi M, Tsai WL. Loss-of-function mutations in TNFAIP3 leading to A20 haploinsufficiency cause an early-onset autoinflammatory disease. Nat Genet. 2015.

132. Daou S, Hammond-Martel I, Mashtalir N, Barbour H, Gagnon J, lannantuono NV, Nkwe NS, Motorina A, Pak H, Yu H, et al. The BAP1/ASXL2 histone $\mathrm{H} 2 \mathrm{~A}$ deubiquitinase complex regulates cell proliferation and is disrupted in cancer. J Biol Chem. 2015;290(48):28643-63.

133. LaFave LM, Beguelin W, Koche R, Teater M, Spitzer B, Chramiec A, Papalexi $E$, Keller MD, HricikT, Konstantinoff $K$, et al. Loss of BAP1 function leads to EZH2-dependent transformation. Nat Med. 2015;21(11):1344-9.

134. Reincke M, Sbiera S, Hayakawa A, Theodoropoulou M, Osswald A, Beuschlein F, Meitinger T, Mizuno-Yamasaki E, Kawaguchi K, Saeki Y. Mutations in the deubiquitinase gene USP8 cause Cushing's disease. Nat Genet. 2015:47(1):31-8.

135. Luise C, Capra M, Donzelli M, Mazzarol G, Jodice MG, Nuciforo P, Viale G, Di Fiore PP, Confalonieri S. An atlas of altered expression of deubiquitinating enzymes in human cancer. PLoS ONE. 2011;6(1):e15891.

136. Oliveira AM, Perez-Atayde AR, Inwards CY, Medeiros F, Derr V, Hsi B-L, Gebhardt MC, Rosenberg AE, Fletcher JA. USP6 and CDH11 oncogenes identify the neoplastic cell in primary aneurysmal bone cysts and are absent in so-called secondary aneurysmal bone cysts. Am J Pathol. 2004;165(5):1773-80.

137. Hussain S, Zhang Y, Galardy P. DUBs and cancer: the role of deubiquitinating enzymes as oncogenes, non-oncogenes and tumor suppressors. Cell Cycle. 2009;8(11):1688-97.

138. Santos MM, Moreira R. Michael acceptors as cysteine protease inhibitors. Mini Rev Med Chem. 2007;7(10):1040-50.

139. Lee B-H, Lee MJ, Park S, Oh DC, Elsasser S, Chen PC, Gartner C, Dimova N, Hanna J, Gygi SP. Enhancement of proteasome activity by a smallmolecule inhibitor of USP14. Nature. 2010;467(7312):179-84.

140. Tian Z, D'Arcy P, Wang X, Ray A, Tai YT, Hu Y, Carrasco RD, Richardson P, Linder S, Chauhan D. A novel small molecule inhibitor of deubiquitylating enzyme USP14 and UCHL5 induces apoptosis in multiple myeloma and overcomes bortezomib resistance. Blood. 2014;123(5):706-16.

141. Aleo E, Henderson CJ, Fontanini A, Solazzo B, Brancolini C. Identification of new compounds that trigger apoptosome-independent caspase activation and apoptosis. Cancer Res. 2006:66(18):9235-44.
142. Zhou B, Zuo Y, Li B, Wang H, Liu H, Wang X, Qiu X, Hu Y, Wen S, Du J. Deubiquitinase inhibition of 195 regulatory particles by 4-arylidene curcumin analog AC17 causes NF-KB inhibition and p53 reactivation in human lung cancer cells. Mol Cancer Ther. 2013;12(8):1381-92.

143. Issaenko OA, Amerik AY. Chalcone-based small-molecule inhibitors attenuate malignant phenotype via targeting deubiquitinating enzymes. Cell Cycle. 2012;11(9):1804-17.

144. Kapuria V, Peterson LF, Fang D, Bornmann WG, Talpaz M, Donato NJ. Deubiquitinase inhibition by small-molecule WP1130 triggers aggresome formation and tumor cell apoptosis. Cancer Res. 2010;70(22):9265-76.

145. Wang Q, Li L, Ye Y. Inhibition of p97-dependent protein degradation by Eeyarestatin I. J Biol Chem. 2008;283(12):7445-54

146. Tian X, Isamiddinova NS, Peroutka RJ, Goldenberg SJ, Mattern MR, Nicholson B, Leach C. Characterization of selective ubiquitin and ubiquitin-like protease inhibitors using a fluorescence-based multiplex assay format. Assay Drug Dev Technol. 2011;9(2):165-73.

147. Chauhan D, Tian Z, Nicholson B, Kumar KG, Zhou B, Carrasco R, McDermott JL, Leach CA, Fulcinniti M, Kodrasov MP, et al. A small molecule inhibitor of ubiquitin-specific protease-7 induces apoptosis in multiple myeloma cells and overcomes bortezomib resistance. Cancer Cell. 2012;22(3):345-58

148. Colland F, Formstecher E, Jacq X, Reverdy C, Planquette C, Conrath S, Trouplin V, Bianchi J, Aushev VN, Camonis J. Small-molecule inhibitor of USP7/HAUSP ubiquitin protease stabilizes and activates p53 in cells. Mol Cancer Ther. 2009;8(8):2286-95.

149. Reverdy C, Conrath S, Lopez R, Planquette C, Atmanene C, Collura V, Harpon J, Battaglia V, Vivat V, Sippl W. Discovery of specific inhibitors of human USP7/HAUSP deubiquitinating enzyme. Chem Biol. 2012;19(4):467-77.

150. Weinstock J, Wu J, Cao P, Kingsbury WD, McDermott JL, Kodrasov MP, McKelvey DM, Suresh Kumar K, Goldenberg SJ, Mattern MR. Selective dual inhibitors of the cancer-related deubiquitylating proteases USP7 and USP47. ACS Med Chem Lett. 2012;3(10):789-92.

151. Altun M, Kramer HB, Willems LI, McDermott JL, Leach CA, Goldenberg SJ, Kumar KS, Konietzny R, Fischer R, Kogan E. Activity-based chemical proteomics accelerates inhibitor development for deubiquitylating enzymes. Chem Biol. 2011;18(11):1401-12.

152. Liu Y, Lashuel HA, Choi S, Xing X, Case A, Ni J, Yeh LA, Cuny GD, Stein RL, Lansbury PT. Discovery of inhibitors that elucidate the role of UCH-L1 activity in the H1299 lung cancer cell line. Chem Biol. 2003;10(9):837-46.

153. Mermerian AH, Case A, Stein RL, Cuny GD. Structure-activity relationship, kinetic mechanism, and selectivity for a new class of ubiquitin C-terminal hydrolase-L1 (UCH-L1) inhibitors. Bioorg Med Chem Lett. 2007;17(13):3729-32.

154. Chen J, Dexheimer TS, Ai Y, Liang Q, Villamil MA, Inglese J, Maloney DJ, Jadhav A, Simeonov A, Zhuang Z. Selective and cell-active inhibitors of the USP1/UAF1 deubiquitinase complex reverse cisplatin resistance in non-small cell lung cancer cells. Chem Biol. 2011;18(11):1390-400.

155. Liu N, Huang H, Dou QP, Liu J. Inhibition of 195 proteasome-associated deubiquitinases by metal-containing compounds. Oncoscience. 2015:2(5):457

156. Ohayon S, Spasser L, Aharoni A, Brik A. Targeting deubiquitinases enabled by chemical synthesis of proteins. J Am Chem Soc. 2012;134(6):3281-9.

157. Edelmann MJ, Nicholson B, Kessler BM. Pharmacological targets in the ubiquitin system offer new ways of treating cancer, neurodegenerative disorders and infectious diseases. Expert Rev Mol Med. 2011;13:e35.

158. Yue W, Chen Z, Liu H, Yan C, Chen M, Feng D, Yan C, Wu H, Du L, Wang Y. A small natural molecule promotes mitochondrial fusion through inhibition of the deubiquitinase USP30. Cell Res. 2014:24(4):482-96. 